\title{
Assessing changes in distribution of the Endangered snow leopard Panthera uncia and its wild prey over 2 decades in the Indian Himalaya through interview- based occupancy surveys
}

\author{
A bhishek Ghoshal, Yash Veer Bhatnagar, Bivash Pandav \\ Koustubh Sharma, Charudutt Mishra \\ R. RaghunATh and KulBhUShansingh R. SURYAWANSHI
}

\begin{abstract}
Understanding species distributions, patterns of change and threats can form the basis for assessing the conservation status of elusive species that are difficult to survey. The snow leopard Panthera uncia is the top predator of the Central and South Asian mountains. Knowledge of the distribution and status of this elusive felid and its wild prey is limited. Using recall-based key-informant interviews we estimated site use by snow leopards and their primary wild prey, blue sheep Pseudois nayaur and Asiatic ibex Capra sibirica, across two time periods (past: 1985-1992; recent: 2008-2012) in the state of Himachal Pradesh, India. We also conducted a threat assessment for the recent period. Probability of site use was similar across the two time periods for snow leopards, blue sheep and ibex, whereas for wild prey (blue sheep and ibex combined) overall there was an $8 \%$ contraction. Although our surveys were conducted in areas within the presumed distribution range of the snow leopard, we found snow leopards were using only $75 \%$ of the area $\left(14,616 \mathrm{~km}^{2}\right)$. Blue sheep and ibex had distinct distribution ranges. Snow leopards and their wild prey were not restricted to protected areas, which encompassed only $17 \%$ of their distribution within the study area. Migratory livestock grazing was pervasive across ibex distribution range and was the most widespread and serious conservation threat. Depredation by free-ranging dogs, and illegal hunting and wildlife trade were the other severe threats. Our results underscore the importance of community-based, landscape-scale conservation approaches and caution against reliance on geophysical and opinion-based distribution maps that
\end{abstract}

AbHishek GhoshaL ${ }^{*}$ (Corresponding author), Yash Veer Bhatnagar $\dagger$, Koustubh Sharma $\dagger$, Charudutt Mishra $\dagger$ R. Raghunath and Kulbhushansingh R. Suryawanshi $\dagger$ Nature Conservation Foundation, 3076/5, IV Cross, Gokulam Park, Mysore, Karnataka 570002, India E-mail abhishek@ncf-india.org

Bivash PANDAV Wildlife Institute of India, Dehradun, Uttarakhand, India

${ }^{\star}$ Also at: Snow Leopard Trust, Seattle, Washington, USA; Wildlife Institute of India, Dehradun, Uttarakhand, India; and Saurashtra University, Rajkot, Gujarat, India

$\dagger$ Also at: Snow Leopard Trust, Seattle, Washington, USA

Received 3 February 2017. Revision requested 28 April 2017.

Accepted 30 June 2017. First published online 25 October 2017. have been used to estimate national and global snow leopard ranges.

Keywords Asiatic ibex, blue sheep, carnivore, occupancy, snow leopard, survey, threat, ungulate

Supplementary material for this article can be found at https://doi.org/10.1017/So030605317001107

\section{Introduction}

The distribution and habitats of some species have been I negatively affected by human activities and developmental pressures globally (Sanderson et al., 2002). Large mammals, especially apex carnivores, are often considered to be umbrella or flagship species for ecosystem conservation (Simberloff, 1998). Large home ranges and habitat specificity tend to make large mammals vulnerable to range contraction and extinction (Ceballos et al., 2005; Michalski \& Peres, 2005). Understanding threats to large mammals and determining their occurrence and changes in distribution are thus important for conservation planning at large spatial scales (MacKenzie et al., 2006; Karanth et al., 2009; Taubmann et al., 2016).

Since the 1960 India has experienced a $194 \%$ increase in its human population alongside rapid economic growth, which has negatively affected mammal species and their habitats (Madhusudan \& Mishra, 2003; Das et al., 2006; Singh \& Bagchi, 2013). Studies at national and regional levels have reported declines in distribution ranges of some common large mammalian species (Karanth et al., 2009; Pillay et al., 2011). In comparison to the large mammals of the Indian peninsula, the distribution and conservation status of the high-altitude large mammalian assemblage have received little scientific attention (Gaston et al., 1983; Mishra et al., 2006). Reliable baseline information on distribution range is lacking even for charismatic and threatened species such as the snow leopard Panthera uncia and its primary prey, blue sheep Pseudois nayaur and Asiatic ibex Capra sibirica, in India (Lovari et al., 2013; Lyngdoh et al., 2014; Snow Leopard Network, 2014).

The snow leopard, which is categorized as Endangered on the IUCN Red List (Jackson et al., 2008), is the top 
predator and flagship species for conservation of the Indian Himalaya (Snow Leopard Network, 2014; Bhatnagar et al., 2016). The Indian Greater and Trans-Himalaya form the southern limit of the global snow leopard distribution range and constitute c. $6 \%$ of the estimated global snow leopard range (Snow Leopard Working Secretariat, 2013). Amongst the five Indian states where snow leopards occur, Himachal Pradesh has c. one-fifth of the potential snow leopard habitat (3,200-5,200 m altitude; Project Snow Leopard, 2008; Snow Leopard Network, 2014), corresponding to c. $20,000 \mathrm{~km}^{2}$. Within Himachal Pradesh a large, contiguous patch of potential snow leopard habitat is constituted by the four regions of Kinnaur (4,454 $\mathrm{km}^{2}$ at 3,200-5,200 $\mathrm{m}$ altitude), Lahaul $\left(4,653 \mathrm{~km}^{2}\right)$, Spiti $\left(4,328 \mathrm{~km}^{2}\right)$ and Pangi $\left(1,181 \mathrm{~km}^{2}\right)$. These regions $\left(14,616 \mathrm{~km}^{2}\right)$ constitute $73 \%$ of the potential snow leopard habitat in Himachal Pradesh. Since the 1980 s considerable socio-economic changes have occurred in these four regions, including improvements in connectivity and the advent and spread of cash crops (e.g. green peas in Spiti and Lahaul, and apples in Kinnaur and Spiti) (Mishra, 2001; Rana et al., 2012; Basannagari \& Kala, 2013). Increased road connectivity along international borders has led to a rise in infrastructure projects and unregulated tourism, especially since 1992, when Kinnaur and Spiti were opened to Indian and international tourists (Snow Leopard Network, 2014).

We conducted a threat assessment and evaluated changes in the distribution of the snow leopard, blue sheep and ibex in these regions over a period of 2 decades. We used multiseason occupancy modelling (MacKenzie et al., 2006) on detection/non-detection data collected by interviewing local people and corrected for imperfect detection across two time periods (Karanth et al., 2009; Pillay et al., 2011; Taubmann et al., 2016), past (1985-1992) and recent (20082012). The method facilitated analysis of data from past and recent time periods based on recall of interviewees. Multiple respondents from a sampling unit were treated as replicate surveys for the primary sampling seasons, thereby accounting for imperfect detection. Thus, sampling difficult-to-detect species across a large area and multiple time periods is possible using this method. We present distribution maps of the snow leopard, blue sheep and ibex for the two time periods, using appropriate covariates. We discuss the implications of our findings in the context of snow leopard conservation programmes at state, national and global levels.

\section{Study area}

The study area comprised $14,616 \mathrm{~km}^{2}$ at 3,200-5,200 m altitude (potential snow leopard habitat, Snow Leopard Network, 2014) covering the contiguous potential snow leopard habitat across the Greater and Trans-Himalaya Mountains in Himachal Pradesh (Fig. 1). The vegetation in the Trans-Himalaya is largely dry alpine steppe (Champion \& Seth, 1968), with gentle-rolling uplands interspersed with steep cliffs and rocky outcrops. The terrain is rugged, with cliffs and sharp ridgelines interspersed with alpine and subalpine tracts in the Greater Himalaya. The south-east and north-west extremes of our study area are characterized by a relatively moist climate and tracts of forest. The entire region is characterized by Palaearctic conditions, with annual temperature ranging from $\mathrm{c} .-40^{\circ} \mathrm{C}$ in winter to $\mathrm{c} .35^{\circ} \mathrm{C}$ in summer. The region is drained by three major rivers, the Sutlej in Kinnaur District, the Spiti in Spiti subdivision and part of northern Kinnaur, and the Chandra-Bhaga or Chenab in Lahaul and Pangi subdivisions.

Given the difficult terrain, limited plant productivity and extreme climate, the local agro-pastoralist communities inhabit the landscape at low densities (one individual per $\mathrm{km}^{2}$ in Lahaul and Spiti; 13 per $\mathrm{km}^{2}$ in Kinnaur; 11 per $\mathrm{km}^{2}$ in Pangi). Kinnaur, Lahaul and Pangi are inhabited primarily by followers of the Hindu religion, with Buddhists inhabiting only the uppermost villages, whereas Spiti is inhabited primarily by Buddhists. Their traditional dependence on natural resources for food (including wildlife), fuel, livestock grazing (sheep, goats, cattle, yaks, yak-cattle hybrids), fodder, construction material and medicinal plants is widespread and varies across the landscape (Mishra, 2001). The regional economy has shifted from a subsistence and barter-based system to being cash-based and marketdriven (Mishra, 2000; Bhatnagar \& Singh, 2011). The advent of the green pea Pisum sativum as a cash crop from 1985 onwards and the opening up of Kinnaur District and Spiti subdivision to tourists in 1992 have accelerated these changes. Development and agricultural intensification are providing job opportunities and attracting non-native labourers to the landscape. Additionally, migratory herders from Shimla, Kangra and Chamba districts graze livestock in the highaltitude pastures across most of the study area during summer (June-August).

Carnivores in the study area include the snow leopard, the wolf Canis lupus and the brown bear Ursus arctos at $>$ 3,000 m altitude, and the common leopard Panthera par$d u s$ and Himalayan black bear Ursus thibetanus at $<3$,000 $\mathrm{m}$ altitude (Jayapal \& Ramesh, 2010; Mishra et al., 2010). Among wild herbivores, the Himalayan tahr Hemitragus jemlahicus, Himalayan serow Capricornis thar, musk deer Moschus leucogaster and Himalayan goral Naemorhedus goral occur in the Greater Himalaya, and blue sheep and Asiatic ibex occur in both the Greater and Trans-Himalaya.

\section{Methods}

\section{Survey design and data collection}

We used key-informant interviews with a structured questionnaire to record occurrences of snow leopards and their prey for two time periods: 1985-1992 and 2008-2012 


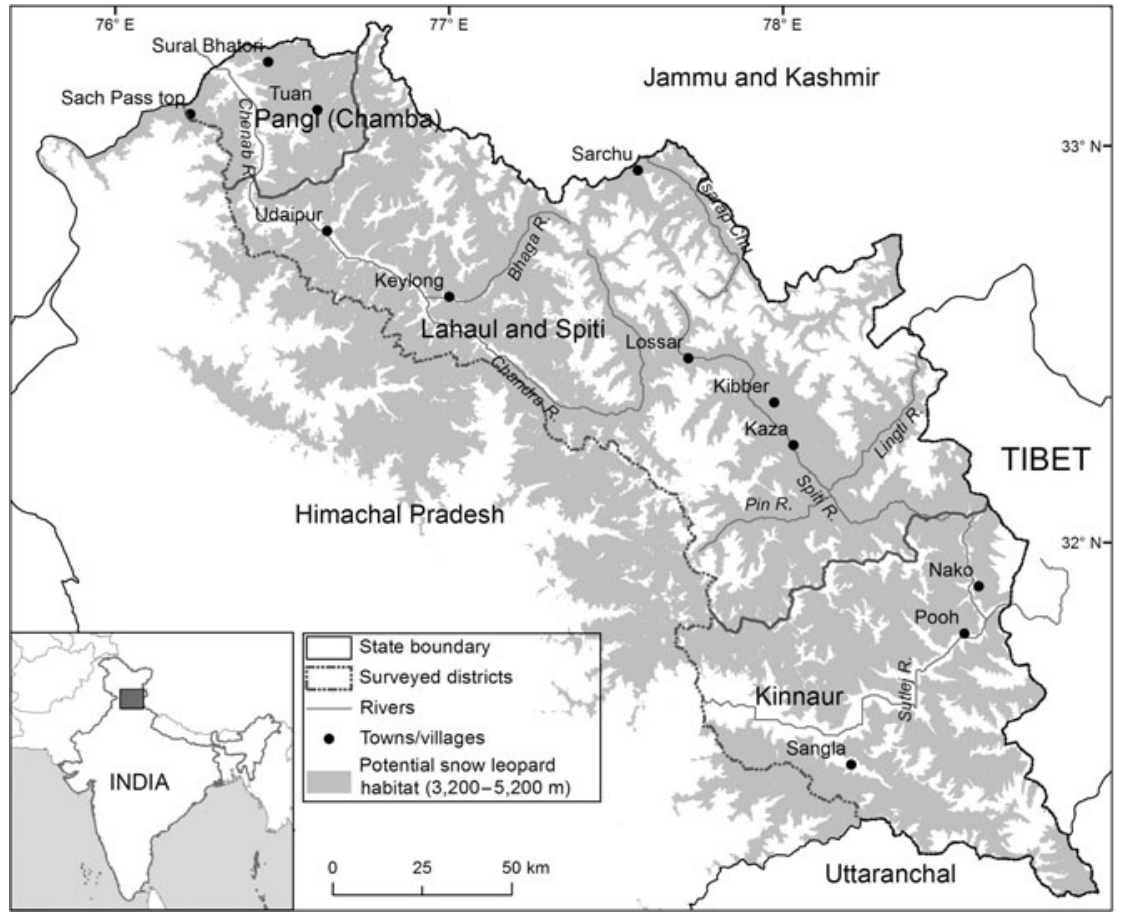

Fig. 1 The locations of Kinnaur, Lahaul and Spiti Districts and Pangi sub-division of Chamba District, in Himachal Pradesh, India. The shaded region denotes 3,2005,200 $\mathrm{m}$ altitude, the potential snow leopard Panthera uncia habitat in Himachal Pradesh. (following Pillay et al., 2011 and Taubmann et al., 2016). The survey was carried out during the summer season (JuneSeptember) of 2012. The study area was divided into 88 grid cells (sites) of $15 \times 15 \mathrm{~km}$ (area $225 \mathrm{~km}^{2}$ ) each, the area being similar to the estimated mean home-range size of the snow leopard (Johansson et al., 2016).

The questionnaire (Supplementary Material S1) contained two sections. The first dealt with information related to the attributes of the respondents that could affect reliable detection of the study species (Table 1), and the second contained questions regarding detections of the study species during the two time periods, including the location, year and approximate month of each detection.

Upon entering a village we first created a focus group of two or three people with thorough knowledge of the site or grid cell. With their help we prepared resource maps (Suryawanshi et al., 2013), with approximate locations of settlements, agricultural areas, pastures, seasonal use of pastures, number of livestock and areas used for biomass extraction. This information was transferred to printed maps of the area. During this exercise we did not record species detection/non-detection, as the reports of one person could be influenced by another in such a group. These respondents and others were later interviewed individually by AG, specifically to gather data on detection/non-detection of snow leopards and their prey. The resource mapping facilitated the plotting of detection locations on a map. The respondents included herders, active and former hunters, cattle herders, medicinal plant collectors, forest department officials, staff and contractual workers, military personnel, tourist guides, porters and photographers. Key informants were shown images of study species among images of numerous other carnivore and mountain ungulate species, such as the Tibetan wolf Canis lupus filchneri, brown bear, common leopard, Himalayan black bear, Himalayan tahr, Himalayan serow, musk deer, Himalayan goral, Kashmir stag or hangul Cervus elaphus hanglu, markhor Capra falconeri, kiang Equus kiang, Tibetan gazelle Procapra picticaudata, Tibetan argali Ovis ammon hodgsoni, wild yak Bos mutus and Ladakh urial Ovis vignei vignei. Respondents who failed to identify study species from the images were excluded from the analyses, as were those who were unable to provide reliable information on location of species detection. The identity of the respondents has been kept confidential.

We identified conservation threats to the snow leopard and its wild prey in Kinnaur, Lahaul, Spiti and Pangi based on discussion with the focus groups and personal observations. The threats were ranked based on area of spread, intensity and urgency, following Margoluis \& Salafsky (2001). We identified fourteen threats in four broad categories, namely, livestock-wild prey interactions, people-wildlife interactions, developmental activities and other human disturbances. For a particular threat in a region, a score of 1-14 was assigned, with 1 indicating low and 14 severe. Thus, total ranking of a threat (sum of scores for area, intensity and urgency) in a region could be 3-42. We considered a score of 3-14 to indicate low threat, 15-28 medium threat, and 29-42 severe threat.

\section{Data analyses}

To define the past time period we chose two landmark events: the introduction of the green-pea crop in Lahaul \& 
TABLE 1 Site and survey covariates used in occupancy analyses to assess changes in distribution of the snow leopard Panthera uncia and wild prey (blue sheep Pseudois nayaur and Asiatic ibex Capra sibirica) between two time periods (1985-1992 and $2008-2012$ in the Greater and Trans-Himalaya of Himachal Pradesh, India (Fig. 1), with description, variable type, and expected relationship with site use and detection probability.

\begin{tabular}{|c|c|c|c|}
\hline & Description & $\begin{array}{l}\text { Variable } \\
\text { type }\end{array}$ & $\begin{array}{l}\text { Expected relationship with site use and detection } \\
\text { probability }\end{array}$ \\
\hline \multicolumn{4}{|l|}{ Site covariates } \\
\hline Altitude & Mean altitude & Continuous & $\begin{array}{l}\text { Positive correlation with site use by study species } \\
\text { up to c. } 5,200 \mathrm{~m} \text { altitude }\end{array}$ \\
\hline Ruggedness & $\begin{array}{l}\text { Proportion of rugged area, using terrain } \\
\text { ruggedness index }\end{array}$ & Continuous & Positive correlation with site use by study species \\
\hline $\begin{array}{l}\text { Normalized difference } \\
\text { vegetation index }\end{array}$ & Proportion of vegetated area & Continuous & $\begin{array}{l}\text { Positive correlation with site use by blue sheep \& } \\
\text { ibex }\end{array}$ \\
\hline $\begin{array}{l}\text { Migratory livestock } \\
\text { grazing }\end{array}$ & $\begin{array}{l}\text { Presence or absence of migratory livestock } \\
\text { grazing }\end{array}$ & Binary & $\begin{array}{l}\text { Negative correlation with site use by blue sheep } \\
\text { and ibex }\end{array}$ \\
\hline Livestock population & Number of sheep/goats & Continuous & $\begin{array}{l}\text { Negative correlation with site use by blue sheep } \\
\text { and ibex }\end{array}$ \\
\hline \multicolumn{4}{|l|}{ Survey covariates } \\
\hline Active & $\begin{array}{l}\text { Whether respondent was active or not during } \\
\text { the primary survey periods }\end{array}$ & Binary & $\begin{array}{l}\text { Active respondents are more likely to encounter } \\
\text { study species }\end{array}$ \\
\hline Time spent & $\begin{array}{l}\text { Number of months in which the respondent } \\
\text { was active in the area of knowledge }\end{array}$ & Continuous & $\begin{array}{l}\text { Respondents spending more time in area of } \\
\text { knowledge are more likely to detect study species }\end{array}$ \\
\hline Familiarity & $\begin{array}{l}\text { Number of years for which the respondent } \\
\text { was familiar with the area of knowledge }\end{array}$ & Continuous & $\begin{array}{l}\text { Respondents with higher familiarity are more } \\
\text { likely to detect study species }\end{array}$ \\
\hline Age & Age of respondent in years & Continuous & Mixed effect on encounter of study species \\
\hline Profession & $\begin{array}{l}\text { Categorical variable representing sedentary, } \\
\text { semi-outdoor \& outdoor work }\end{array}$ & Categorical & $\begin{array}{l}\text { Respondents with outdoor work are more likely } \\
\text { to detect study species }\end{array}$ \\
\hline
\end{tabular}

Spiti in 1985, and the opening up of Kinnaur and Spiti to tourists in 1992. We defined the recent time period as the 5-year period prior to our survey (2008-2012). As 5 years is a considerably long period to assume population closure within sampled units, we assumed that the occupancy estimates would reflect the probability of the sites being used by the study species in the respective time periods. This interpretation of the conventional occupancy estimate as the probability of site use allows for changes within the sampling units and relaxation of the closure assumption (MacKenzie et al., 2006; Taubmann et al., 2016). This design assumes that the changes in probability of site use within each sampling unit during each sampling period were random and described by the specific covariates applied. Probability of colonization $(\gamma)$ was estimated as the probability of a site that was not used by a species during the past time period being used during the recent time period, whereas probability of extinction $(\varepsilon)$ was estimated as the probability of a site that was used by a species during the past time period not being used during the recent time period (MacKenzie et al., 2003). The probabilities of local colonization and local extinction can be interpreted as probability of distribution expansion and contraction, respectively, between the two periods.

Data on sightings of snow leopards, blue sheep and ibex gathered during interviews were arranged in a detection/ non-detection (1/0) framework for past and recent time periods. Each interviewee's report from a particular site was assigned as a replicate survey within the site. Site covariates that could influence probability of site use by a species were modelled using logistic insertions (Table 1 ). Topographic covariates such as mean altitude above mean sea level, and proportions of rugged area in a site (terrain ruggedness index) and vegetated area in a site (normalized difference vegetation index) were generated using Shuttle Radar Topographic Mission (SRTM) and Landsat data, respectively. As snow leopards are known to occur between 3,200 $\mathrm{m}$ (above the tree line) and 5,200 $\mathrm{m}$ (approximate lower limit of permafrost and limit of vegetation growth) in the Western Himalaya (Project Snow Leopard, 2008; Snow Leopard Network, 2014), we used mean altitude and its square to model probability of site use as a linear and quadratic function of altitude. We expected probability of site use to be higher in sites with a greater proportion of terrain ruggedness (Snow Leopard Network, 2014; McCarthy \& Mallon, 2016). A higher proportion of vegetated area was expected to favour the distribution of wild prey. Presence of migratory livestock grazing reflected areas that were used for grazing only during the peak summer (mid June-mid August) and were far from villages, and hence not grazed by local livestock. Presence of migratory livestock grazing was expected to lower the probability of site use by wild prey. The livestock population (i.e. the number of sheep/ goats in a site) was expected to negatively influence 
probability of site use by wild prey. If the confidence interval of the coefficient of a variable included zero we interpreted it as a statistically non-significant association.

Covariates that might have influenced the probability of detection of a species and its reporting to the researcher were used as survey covariates to model detection probability (Table 1). These included respondent age, profession, duration (in years) of familiarity with the area for which they were providing information, time spent in that area annually, and a binary variable indicating whether or not a respondent visited snow leopard and prey habitat during each time period.

We modelled probability of site use and detection probability through single-species multi-season models for snow leopards, blue sheep and ibex, using Presence 10.9 (MacKenzie et al., 2003; Hines, 2006). We parameterized our models to estimate empirically historical and recent probabilities of site use and probability of distribution expansion. Estimates of probabilities of distribution contraction were derived. Models were ranked in ascending order based on the Akaike information criterion (AIC, Akaike, 1973; Burnham \& Anderson, 2002).

Our analyses yielded multiple models with similar AIC values, thus indicating that no one model, by itself, could explain the observed variation in the data adequately. Thus, following a multi-model inference approach (Burnham \& Anderson, 2002), we considered a set of models with a cumulative Akaike weight of $\geq 0.95$ to yield the best approximating model by using model averaging (Burnham \& Anderson, 2002; Symonds \& Moussalli, 2011). Models that did not converge were dropped from the model set before model averaging. We plotted the model-averaged estimates of past and recent occupancy to develop probabilistic maps of past and recent distributions of the snow leopard and its wild prey.

\section{Results}

We carried out 351 systematic key-informant interviews across Kinnaur, Lahaul, Spiti and Pangi. For analyses we used 349 of these interviews, having excluded two respondents who provided unreliable information. Respondents reported detection/non-detection of snow leopards and their wild prey from a mean of 2 grids per respondent (range 1-7). The mean number of respondents who reported sighting snow leopards per grid was $6.64 \pm \mathrm{SD} 4.70$ (range 1-30), whereas the mean number who reported sighting wild prey was $7.60 \pm$ SD 5.34 (range 1-33). Detection data for each species are summarized in Table 2. We developed 31 competing single-species multi-season occupancy models for the snow leopard, 35 for all wild prey combined, 37 for blue sheep and 33 for ibex (Supplementary Table S1).

Naïve estimates of the proportion of sites used by snow leopards in the past and recent time periods were 0.37 and
TABLE 2 Number of detections, and number of respondents reporting detections, of snow leopards, wild prey (cumulative detections of blue sheep and ibex), blue sheep and ibex in the Greater and Trans-Himalaya of Himachal Pradesh, India (Fig. 1). Multiple respondents reported both blue sheep and ibex from more than one grid, and therefore the detections of wild prey sum to more than the detections of individual species.

\begin{tabular}{lrllll}
\hline & \multicolumn{2}{l}{} & & \multicolumn{2}{l}{$\begin{array}{l}\text { No. of } \\
\text { respondents }\end{array}$} \\
\cline { 2 - 3 } \cline { 6 - 7 } & Past & Recent & & Past & Recent \\
\hline Snow leopard & 54 & 110 & & 24 & 30 \\
Wild prey & 330 & 351 & & 27 & 33 \\
Blue sheep & 51 & 144 & & 27 & 33 \\
Ibex & 55 & 214 & & 27 & 33 \\
\hline
\end{tabular}

0.49, respectively. Naïve estimates of the proportion of sites used by wild prey in the past and recent time periods were 0.87 and 0.80 , respectively. When analysed individually, naive estimates of the proportion of sites used by blue sheep in the past and recent time periods were 0.26 and 0.34 , and by ibex 0.34 and 0.52 , respectively.

\section{Detection probability}

According to null models the detection probabilities of snow leopards, blue sheep, ibex and wild prey were $0.24 \pm \mathrm{SE} 0.02$, $0.38 \pm$ SE $0.02,0.39 \pm$ SE 0.02 and $0.62 \pm$ SE 0.015 , respectively. When modelled with survey covariates, detection probabilities of snow leopards, wild prey, blue sheep and ibex varied between the past (1985-1992) and recent (2008-2012) time periods (Table 3). Age of respondent showed a weak negative effect on detections of snow leopards, blue sheep and wild prey. Familiarity with the area of knowledge was an important factor for ibex detection. Time spent each year by a respondent in the area of survey had little effect on detection probability. The profession of the respondent had a positive effect on detection probability for all species.

\section{Site use, and expansion or contraction of distribution: snow leopard}

The model-averaged estimate of probability of site use by snow leopards was $0.74 \pm$ SD 0.10 (range $0.47 \pm$ SE 0.30 to $0.92 \pm \mathrm{SE} 0.11$ ) for the past time period and $0.75 \pm \mathrm{SD} 0.10$ (range $0.48 \pm$ SE 0.71 to $0.92 \pm$ SE 0.10) for the recent time period (Fig. 2a,b). Probability of site use by snow leopards showed weak positive correlation with the terrain ruggedness index $\left(\beta_{\text {tri }}=0.89 \pm\right.$ SE 0.52; 95\% CI $\left.-0.14-1.90\right)$ and altitude $\left(\beta_{\text {alt.mean }}=0.73 \pm\right.$ SE $0.73 ; \quad 95 \%$ CI $\left.-0.70-2.16\right)$ (Table 3); however, the coefficients were not statistically significant. In the $75 \%$ of the area used by snow leopards, the probability of site use by snow leopards was relatively high 
TABLE 3 Untransformed estimates of coefficients $(\beta)$ from the top models of snow leopard, wild prey, blue sheep and ibex model sets.

\begin{tabular}{|c|c|c|c|c|}
\hline Model $^{*}$ & $\begin{array}{l}\text { Snow leopard } \\
\beta \pm \mathrm{SE}\end{array}$ & $\begin{array}{l}\text { Blue sheep } \\
\beta \pm \mathrm{SE}\end{array}$ & $\begin{array}{l}\text { Ibex } \\
\beta \pm \mathrm{SE}\end{array}$ & $\begin{array}{l}\text { Wild prey } \\
\beta \pm \mathrm{SE}\end{array}$ \\
\hline Intercept $(\psi) \_$psil & $1.27 \pm 0.42$ & $0.97 \pm 0.42$ & $-0.77 \pm 0.32$ & $3.44 \pm 0.66$ \\
\hline Intercept $(\psi) \_$psi2 & $1.27 \pm 0.42$ & $0.97 \pm 0.42$ & $-0.77 \pm 0.32$ & $2.26 \pm 0.46$ \\
\hline Altitude & $0.73 \pm 0.73$ & $-0.36 \pm 0.34$ & & $-1.13 \pm 0.52$ \\
\hline Altitude_squared & & & & $-0.49 \pm 0.19$ \\
\hline Migratory livestock grazing & & $-2.67 \pm 0.61$ & $4.26 \pm 1.01$ & \\
\hline Ruggedness & $0.89 \pm 0.52$ & & & \\
\hline Intercept $(\gamma)$ & $-0.75 \pm 0.96$ & $-3.54 \pm 0.98$ & $-1.53 \pm 0.52$ & $-1.39 \pm 1.29$ \\
\hline Intercept $(p 1)$ & $-2.59 \pm 0.26$ & $-1.89 \pm 0.23$ & $-1.30 \pm 0.16$ & $0.54 \pm 0.13$ \\
\hline Intercept $(p 2)$ & $0.58 \pm 0.21$ & $1.21 \pm 0.21$ & $1.21 \pm 0.19$ & $-0.52 \pm 0.13$ \\
\hline Age & $-0.06 \pm 0.02$ & $-0.06 \pm 0.01$ & & $-0.03 \pm 0.01$ \\
\hline Familiarity & $0.04 \pm 0.02$ & & $-0.05 \pm 0.01$ & $0.01 \pm 0.01$ \\
\hline Time spent & $0.02 \pm 0.01$ & & & \\
\hline Prof1 & $1.30 \pm 0.27$ & $0.32 \pm 0.29$ & & $0.28 \pm 0.17$ \\
\hline Prof2 & $1.36 \pm 0.25$ & $1.12 \pm 0.23$ & & $0.39 \pm 0.14$ \\
\hline
\end{tabular}

${ }^{*} \Psi$, Probability of site use; $\gamma$, probability of distribution expansion; $p 1$, probability of detection for the past time period; $p 2$, probability of detection for the recent time period; psi1, past probability of site use; psi2, recent probability of site use. Site covariates: altitude, mean altitude of a site; altitude_squared, square of mean altitude; Ruggedness, proportion of rugged area in a site, derived from terrain ruggedness index; Migratory livestock grazing, presence (1)/ absence (o) of migratory livestock grazing in a site; Age, age of respondent in years; Familiarity, no. of years or months for which a respondent is familiar with the area of knowledge; Time spent, time spent in months or days by a respondent in the area of knowledge per year; Profi, sedentary profession (e.g. office worker); Prof2, sedentary and outdoor profession (e.g. forest guard).

$(>0.50)$. A relatively higher probability of site use $(>0.70)$ was recorded in Spiti and in the majority of Kinnaur. Central and western Lahaul and Pangi had relatively low probabilities of site use by snow leopards (Fig. 2a,b). There was no clear evidence of expansion of the snow leopard's distribution ( $\gamma=0.31 \pm$ SE 0.24; 95\% CI -2.63-1.13). The estimated probability of contraction of the snow leopard's distribution was $0.04 \pm$ SD 0.05 , indicating no clear evidence for overall contraction, and ranged between $0.03 \pm$ SE 0.04 and $0.41 \pm$ SE 0.97 (Supplementary Fig. S2).

Site use, and expansion or contraction of distribution: blue sheep

The model-averaged estimate of probability of site use by blue sheep was $0.42 \pm \mathrm{SD} 0.28$ (range $0.12 \pm \mathrm{SE} 0.07$ to $0.87 \pm \mathrm{SE}$ 0.12 ) for the past time period and $0.41 \pm$ SD 0.28 (range 0.11 \pm SE 0.06 to $0.86 \pm \mathrm{SE} 0.13$ ) for the recent time period (Fig. 3a,b). Probability of site use by blue sheep showed a negative correlation with migratory livestock grazing $\left(\beta_{\text {migrh }}=-2.67 \pm \mathrm{SE} 0.61 ; 95 \% \mathrm{CI}-3.87\right.$ to -1.47 ; Table 3$)$. There were no clear relationships between probability of site use by blue sheep and altitude $\left(\beta_{\text {alt.mean }}=-0.36 \pm\right.$ SE 0.34; 95\% CI $-1.02-0.30)$ or ruggedness $\left(\beta_{\text {tri }}=0.03 \pm \mathrm{SE}\right.$ 0.53; 95\% CI -1.02-1.06; Table 3). A high probability of site use $(>0.50)$ by blue sheep was estimated in the majority of Spiti and Kinnaur. South-western Spiti and all of Lahaul and Pangi showed low probabilities of site use $(<0.50)$ by blue sheep (Fig. 3a,b). We found no clear evidence of probability of expansion of blue sheep distribution $(\gamma=0.03 \pm \mathrm{SE}$ 0.03; 95\% CI - 0.03-0.09). The estimated probability of contraction of blue sheep distribution was $0.01 \pm \mathrm{SD} 0.05$ (range $0.01 \pm \mathrm{SE} 0.03$ to $0.21 \pm \mathrm{SE} 0.22$ ), indicating no clear evidence for overall contraction (Supplementary Fig. S2).

Site use, and expansion or contraction of distribution: Asiatic ibex

The estimated probability of site use by ibex was the same for past and recent time periods $(\psi=0.61 \pm \mathrm{SD} \pm 0.28$; range: 0.30 \pm SE 0.08 to $0.97 \pm$ SE 0.03; Fig. 3c,d). Probability of site use by ibex showed a positive correlation with migratory livestock grazing $\left(\beta_{\text {migrh }}=4.26 \pm\right.$ SE 1.01; 95\% CI 2.28-6.24; Table 3). The relationship between ibex site use and mean altitude was unclear $\left(\beta_{\text {alt.mean }}=-0.20 \pm\right.$ SE 0.31; 95\% CI -0.81-0.41) (Table 3$)$. High probability of site use $(>0.50)$ by ibex was found in Lahaul and Pangi, and in south-western parts of Spiti and Kinnaur. Central, south and eastern Spiti, and northern, eastern and south-eastern Kinnaur showed low probabilities of site use $(<0.50)$ by ibex (Fig. $3 \mathrm{C}, \mathrm{d})$. There was no clear evidence for expansion of ibex distribution across the study area $(\gamma=0.18 \pm$ SE 0.10; 95\% CI - 0.02$0.38)$. The estimated probability of contraction of ibex distribution was $0.003 \pm$ SD 0.04 (range $0.006 \pm$ SE 0.006 to $0.44 \pm$ SE 0.26), indicating no clear evidence for overall contraction (Supplementary Fig. S2).

Site use, and expansion or contraction of distribution: wild prey

The model-averaged estimate of probability of site use by wild prey (blue sheep and ibex combined) was 

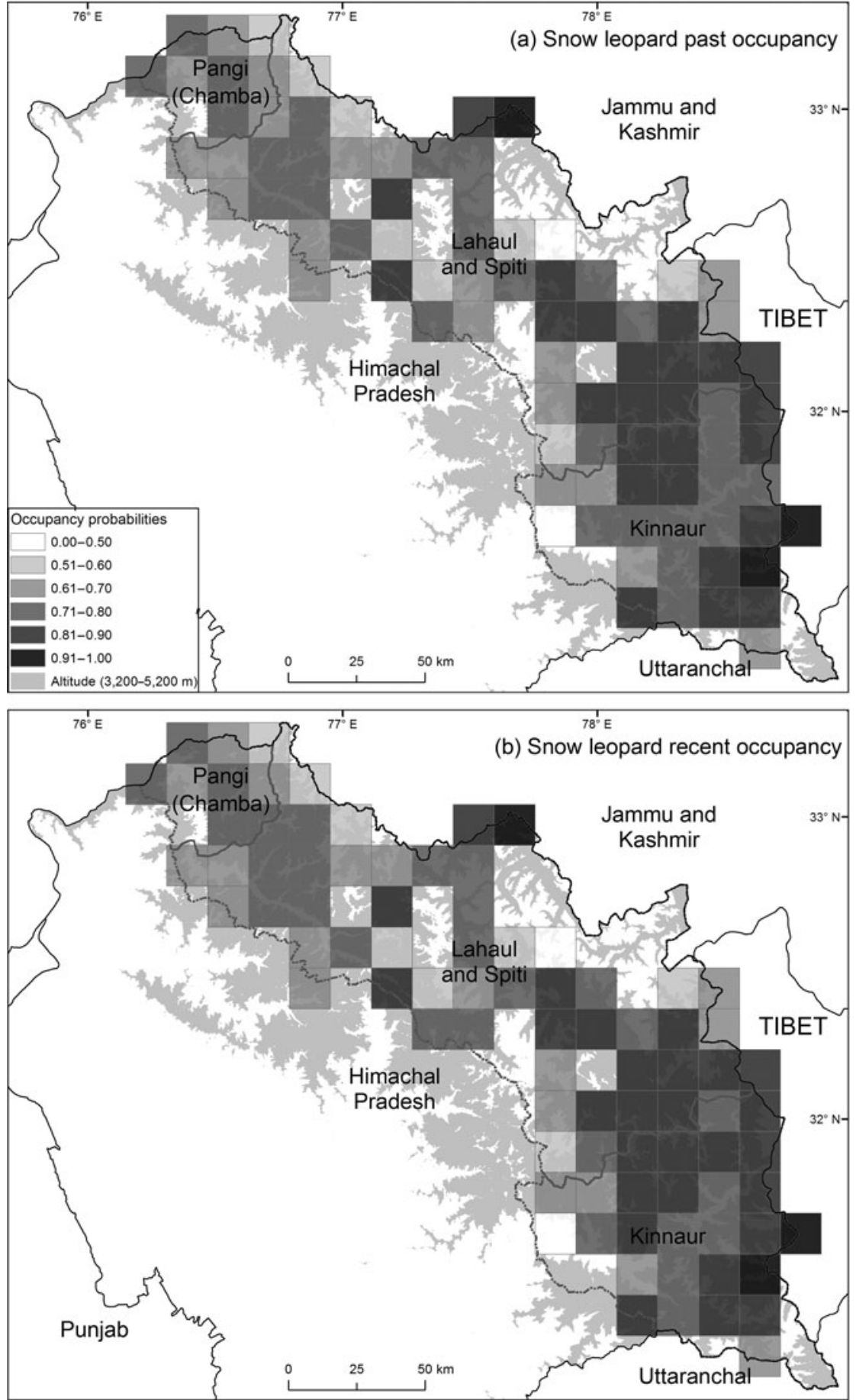

FIg. 2 (a) Past and (b) recent probability of site use (occupancy) by snow leopards across the Greater and Trans-Himalaya mountains of Kinnaur, Lahaul, Spiti and Pangi, Himachal Pradesh, India.
$0.94 \pm$ SD 0.04 (range $0.80 \pm \mathrm{SE} 0.27$ to $0.98 \pm \mathrm{SE} 0.02$ ) for the past time period and $0.86 \pm \mathrm{SD} 0.08$ (range $0.59 \pm \mathrm{SE}$ 0.66 to $0.94 \pm \mathrm{SE} \mathrm{0.07)}$ for the recent time period. Probability of site use by wild prey varied as a quadratic function of altitude $\left(\beta_{\text {alt.mean }}=-1.13 \pm\right.$ SE 0.53, 95\% CI -2.15 to $-0.11 ; \beta_{\text {alt.sq }}=-0.49 \pm$ SE $0.19 ; 95 \% \mathrm{CI}-0.86$ to $-0.12)$, and increased with ruggedness $\left(\beta_{\text {tri }}=0.70 \pm\right.$ SE 0.35; 95\% CI 0.01-1.39). There was no clear relationship between probability of site use by wild prey and proportion of vegetated area (normalized difference vegetation index) $\left(\beta_{\text {ndvi }}=-0.26 \pm\right.$ SE 0.43; 95\% CI $\left.-1.10-0.58\right)$ or presence/ absence of migratory livestock grazing $\left(\beta_{\text {migrh }}=-0.12 \pm \mathrm{SE}\right.$ $0.67 ; 95 \%$ CI $-1.44-1.30$; Table 3 ). The probability of site use by wild prey was high $(>0.50)$ in most of the study area. Central Lahaul, parts of northern Spiti and parts of Kinnaur (especially along the Sutlej River valley) showed relatively lower probabilities of site use by wild prey $(<0.50)$. There was no clear evidence for expansion of the 


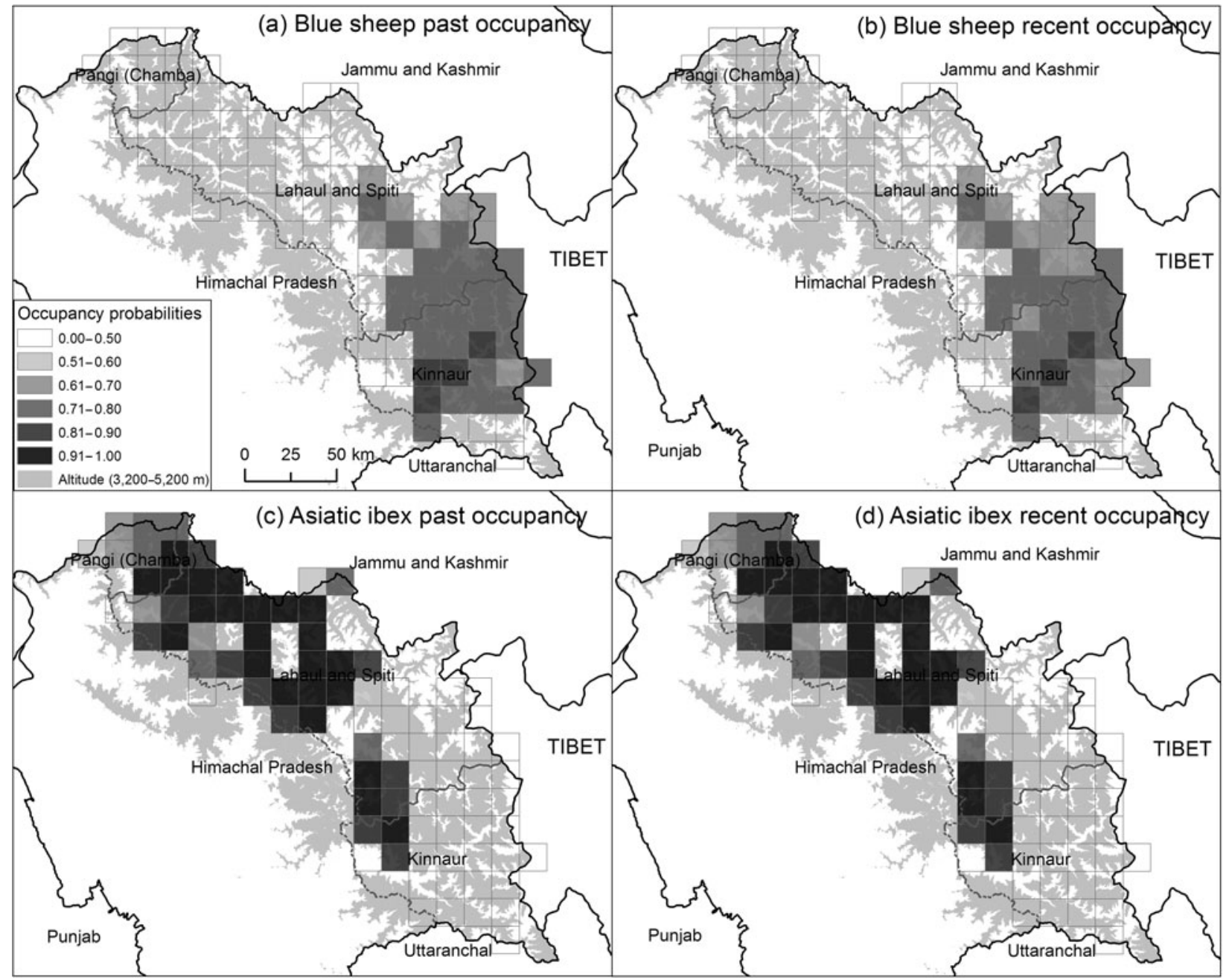

FIG. 3 Past and recent probability of site use (occupancy) by blue sheep (a \& b) and Asiatic ibex (c \& d) across the Greater and Trans-Himalaya mountains of Kinnaur, Lahaul, Spiti and Pangi, Himachal Pradesh, India.

distribution of wild prey $(\gamma=0.22 \pm$ SE $0.30 ; 95 \%$ CI $-3.51-$ 1.14). The estimated probability of contraction of the distribution of wild prey was $0.20 \pm \mathrm{SD} 0.17$ (Supplementary Fig. S2), indicating evidence for a marginal overall contraction of distribution (range $0.04 \pm \mathrm{SE} 0.03$ to $0.32 \pm \mathrm{SE} 0.21$ ). The probability of contraction of the distribution of wild prey was relatively high $(\varepsilon>0.20)$ in $11 \%$ of the sites. These areas were in western Lahaul, northern and eastern Spiti, south-western Spiti and Kinnaur (Supplementary Fig. S2).

\section{Conservation threats}

Threat assessment (Table 4; Supplementary Fig. S1) indicated the major threats across the study area were reduced prey as a result of competition with both local and migratory livestock, reduced prey as a result of subsistence hunting by local communities, illegal hunting and wildlife trade by both local and immigrant labourer and migratory communities, and depredation of wildlife and livestock by free-ranging dogs.

In Kinnaur the severe threats identified were reduced prey as a result of competition with local livestock and subsistence hunting by the local community, illegal hunting and wildlife trade by immigrant labourer and migratory communities, and depredation by dogs. Local livestock grazing was practised in and around villages all across Kinnaur, whereas migratory livestock grazing was prevalent in south-eastern and south-western Kinnaur (Supplementary Fig. S1). Southern and south-western Kinnaur also experienced hunting and wildlife trade by local and migratory herder communities and immigrant labourers. The depredation of wildlife and livestock by free-ranging dogs was found to be widespread.

In Spiti reduced prey as a result of competition with local and migratory livestock, and depredation by dogs, were severe threats. Local livestock grazing was widespread except in a few villages in eastern Spiti on the left bank of the Spiti River. Migratory livestock grazing was prevalent in north- 
TABLE 4 Threat ranking ( $1=$ low threat; $14=$ severe threat) based on area (how widespread is the threat; $1=$ least widespread; $14=$ most widespread), intensity (how severe is the threat; $1=$ low severity; 14 = high severity) and urgency (how immediate/urgent is the threat; 1 = least urgent; 14 = most urgent), following Margoluis \& Salafsky (20o1), for Kinnaur, Lahaul, Spiti and Pangi, Himachal Pradesh, India (Fig. 1). Light grey shading indicates a low level of threat, medium grey indicates a medium level of threat, and dark grey indicates a severe level of threat.

\begin{tabular}{|c|c|c|c|c|c|c|c|c|c|c|c|c|c|c|c|c|}
\hline \multirow[b]{2}{*}{ Threat } & \multicolumn{4}{|c|}{ Kinnaur } & \multicolumn{4}{|l|}{ Spiti } & \multicolumn{4}{|c|}{ Lahaul } & \multicolumn{4}{|c|}{ Pangi (Chamba) } \\
\hline & Area & Intensity & Urgency & $\begin{array}{l}\text { Total } \\
\text { ranking }\end{array}$ & Area & Intensity & Urgency & $\begin{array}{l}\text { Total } \\
\text { ranking }\end{array}$ & Area & Intensity & Urgency & $\begin{array}{l}\text { Total } \\
\text { ranking }\end{array}$ & Area & Intensity & Urgency & $\begin{array}{l}\text { Total } \\
\text { ranking }\end{array}$ \\
\hline
\end{tabular}

\section{Livestock-wild prey interactions}

Prey reduction as a result 14

of competition with local

livestock

Prey reduction as a result

of competition with mi-

gratory livestock

Prey reduction as a result

of disease transmitted by

(3)

livestock

People-wildlife interactions

Retaliatory killing of 2

snow leopards \& wild

prey by local community

Prey reduction as a result 13

of subsistence hunting

by local community

Illegal hunting \& wildlife

trade by local

community

Illegal hunting \& wildlife 12

trade by immigrant

labourer \& migratory

communities

Developmental activities

Impacts of roads on

snow leopard habitat

Impacts of hydro-electric

projects on snow leopard

habitat

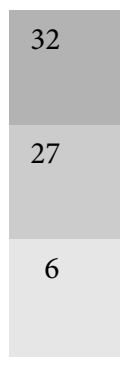

$\begin{array}{ccc}13 & 13 & 4 \\ 12 & 14 & 9 \\ 5 & 6 & 3\end{array}$

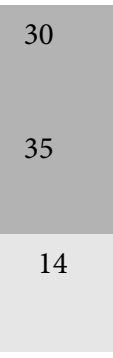

$\begin{array}{rrr}7 & 3 & 4 \\ 14 & 14 & 10 \\ 2 & 2 & 2\end{array}$

17

30

29

37

37

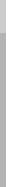

65

$3 \quad 2$

$4 \quad 4$

$7 \quad 8$

(2)

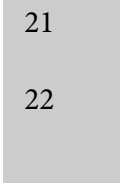

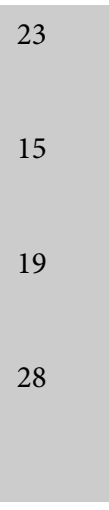

3

8

$10 \quad 10$

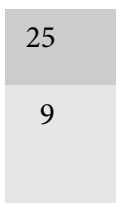

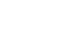

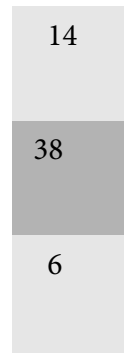

3
14
5

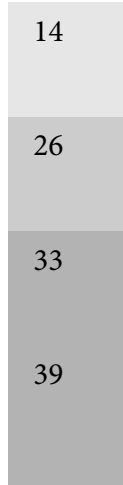

4

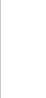

10

$10 \quad 12$

5

12

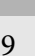

9
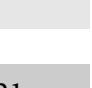

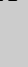

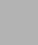

\begin{tabular}{l|lll|l}
17 & 7 & 6 & 7 & 20 \\
25 & 6 & 5 & 6 & 17
\end{tabular}




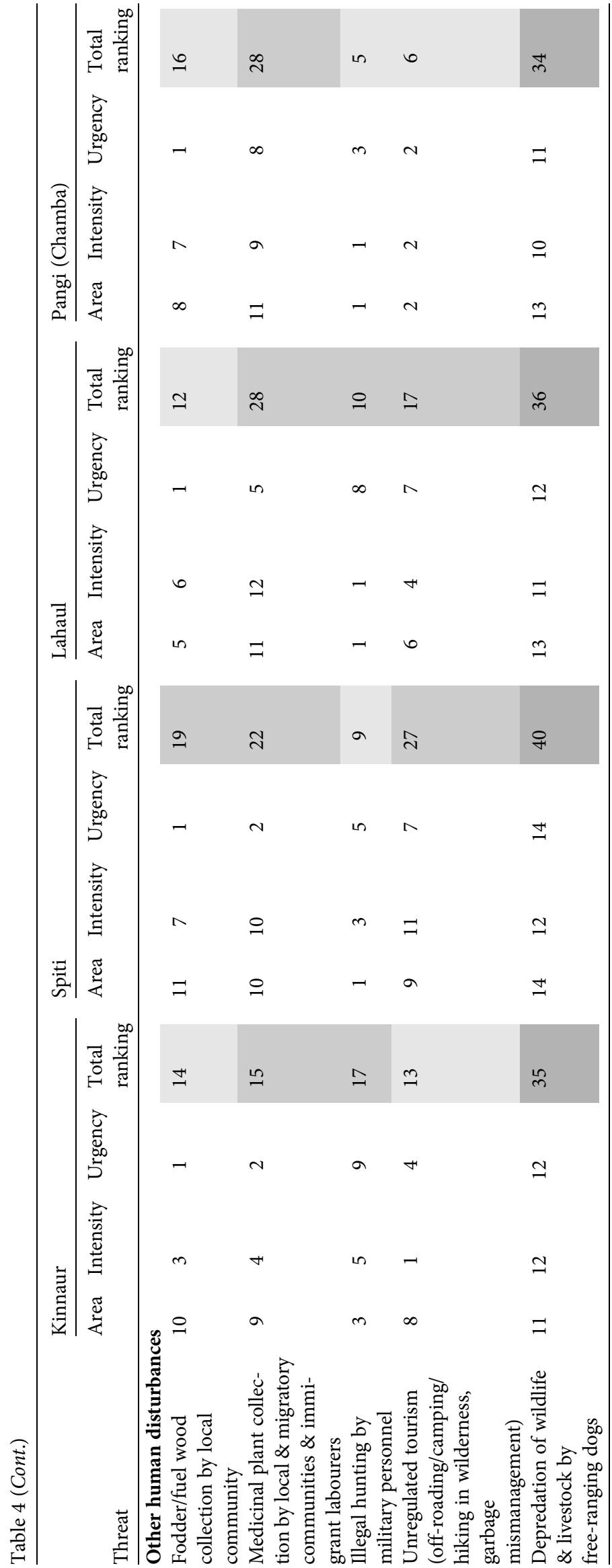

western, western and south-western Spiti (Supplementary Fig. S1). Depredation of wildlife and livestock by freeranging dogs is an emerging conservation threat in Spiti.

In Lahaul reduced prey as a result of competition with migratory livestock, illegal hunting and wildlife trade by the local community, and immigrant labourer and migratory communities, and depredation by dogs, were the severe threats. Migratory livestock grazing was pervasive at relatively high densities (Supplementary Fig. S1). Areas grazed by migratory livestock were also prone to illegal hunting by migratory herders and depredation of wildlife by dogs (migratory herders are accompanied by guard dogs). Hunting was prevalent among the local community of western Lahaul. Immigrant labour camps were abundant along major roadways in Lahaul, and our respondents consistently reported labourers to be involved in illegal hunting and wildlife trade.

In Pangi the severe threats were reduced prey as a result of competition with migratory livestock and subsistence hunting by the local community, illegal hunting and wildlife trade by the local community and immigrant labourer and migratory communities, and depredation by dogs. Similar to Lahaul, migratory livestock grazing was widespread in Pangi and these areas experienced illegal hunting and depredation of wildlife by free-ranging dogs. Hunting for subsistence and for wildlife trade, by both local people and immigrant labourers, was prevalent.

\section{Discussion}

We set out to examine changes in distribution of the snow leopard and its wild prey, and their current conservation status across the Greater and Trans-Himalaya Mountains of Himachal Pradesh between two time periods, past (1985-1992) and recent (2008-2012). We used a recall-based key-informant survey to collect information on detection/ non-detection of snow leopards and their wild prey over the two periods. These data were analysed using a singlespecies, multi-season site-occupancy framework accounting for imperfect detection. We recommend caution in interpreting the effects of variables on site use as causation. For example, normalized difference vegetation index data were used to represent the proportion of vegetated area in a site; however, these data need not represent palatable forage for wild prey, and may explain the absence of a significant positive relationship between proportion of vegetated area and site use by wild prey.

Our results suggest that snow leopard distribution remained largely unchanged between the two time periods, as we did not find any evidence of overall expansion or contraction of snow leopard distribution in the study area, whereas there was a marginal contraction in the distribution of wild prey (blue sheep and ibex combined). Snow leopard 
distribution essentially overlapped with wild prey distribution, with blue sheep and ibex showing mutually exclusive distributions with marginal overlap.

Within our study area we recorded high probabilities of snow leopard site use across large patches in Spiti and Kinnaur (Fig. 2). These were areas where migratory livestock grazing either did not occur or occurred at low intensity, and the intensity of other threats, such as hunting and natural resource extraction, was also low (Table 4; Supplementary Fig. S1). Among areas that showed a relatively high probability of contraction of snow leopard distribution (Supplementary Fig. S2), $82 \%$ were in south-western parts of Kinnaur and Spiti that experienced migratory livestock grazing and hunting by local and migratory people as well as by immigrant labourers. Migratory grazing was prevalent in c. $51 \%$ of the snow leopard's distribution within our study area (Supplementary Fig. S1), and was relatively intense (c. 90 livestock per $\left.\mathrm{km}^{2}\right)$ in c. $40 \%$ of the area, especially in Lahaul and Pangi (Supplementary Fig. S1). Intense migratory livestock grazing, along with hunting by migratory herders and immigrant labourers in Lahaul continue to be serious threats to the otherwise contiguous snow leopard habitat, from Pangi to the west, Spiti to the east and Kinnaur to the south-east. Our study area is also contiguous with the snow leopard habitats of Hemis in Ladakh (Jammu and Kashmir) to the north.

We found that within our study area $25 \%$ of the area traditionally considered to be potential snow leopard habitat (Project Snow Leopard, 2008; Snow Leopard Network, 2014) had a negligible probability of use by snow leopards. This is despite the fact that areas above 5,200 m altitude (mainly rocky areas with snow and ice) and below 3,200 m (forested zone) were excluded from our survey. Large-scale projections of snow leopard distributions and populations have relied on extrapolation of information based on opinions and geophysical modelling (e.g. Snow Leopard Working Secretariat, 2013; Snow Leopard Network, 2014; McCarthy \& Mallon, 2016). Our results caution against such extrapolations, as they are likely to substantially overestimate snow leopard occurrence.

Blue sheep and ibex distributions in our study area were largely mutually exclusive, overlapping marginally along the Sutlej and Spiti Rivers (Fig. 3). Blue sheep occurred in the eastern and south-eastern parts of the study area, which are less rugged, with rolling mountains (Fig. 3a,b). Ibex occurred in the western and south-western parts of the study area, which are more rugged, with steeper mountains (Fig. 3c,d). Thus, in Himachal Pradesh, blue sheep and ibex provide an important prey base for snow leopards, in mostly mutually exclusive areas (Suryawanshi et al., 2013). We found that the overall distribution of wild prey appeared to have declined by $8 \%$ between the two study periods. Areas where contraction occurred (Supplementary Fig. S2), similar to areas with contraction of snow leopard distribution, were in south-western Kinnaur, and central and western
Lahaul, which experienced intense migratory livestock grazing, widespread presence of free-ranging dogs, and illegal hunting and wildlife trade by local and migratory herder communities and immigrant labourers (Table 4; Supplementary Fig. S1).

Across Pangi, Lahaul and northern and south-western Spiti, the ibex is the only large wild prey of the snow leopard. These are also the areas where migratory livestock grazing, depredation by free-ranging dogs, and illegal hunting and wildlife trade by local and migratory herder communities and immigrant labourers are pervasive and intense (Table 4; Supplementary Fig. S1). Migratory livestock grazing is a long-standing, widespread and continually changing practice (Saberwal, 1996; Axelby, 2007) in parts of Kinnaur and Spiti and all of Lahaul and Pangi, covering almost the entire estimated ibex distribution. The use by migratory herders of these relatively steep areas, which are also the habitats of the ibex, resulted in a positive correlation between probability of site use by ibex and the presence of migratory livestock grazing. There is evidence of interference competition between migratory livestock and ibex (Bagchi et al., 2004). Migratory livestock displace ibex from pastures through forage removal and direct disturbance. Understanding impacts of migratory livestock grazing on forage availability and ibex densities (exploitative competition) at a finer spatial scale would be useful.

Blue sheep occur extensively and at relatively high densities in Spiti, especially along the eastern bank of the Spiti River and parts of the western bank (Suryawanshi et al., 2012), where the terrain is relatively gentle and ibex are largely absent. These are also areas used only for local livestock grazing rather than migratory livestock grazing (USL, 2011), hence the negative correlation between site use by blue sheep and migratory livestock grazing.

Snow leopards and wild prey occurred in large parts of our study area and were not restricted to the seven protected areas that cover $18 \%\left(3,875 \mathrm{~km}^{2}\right)$ of the area. Himachal Pradesh thus mirrors a global pattern (Johansson et al., 2016) in which large parts (c. 10,336 $\mathrm{km}^{2}$ ) of snow leopard and wild prey distribution lie outside protected areas. This makes landscape-scale participatory conservation approaches, such as India's Project Snow Leopard (2008) implemented in the Upper Spiti Landscape of Himachal Pradesh (USL, 2011), and the Global Snow Leopard and Ecosystem Protection Program (Snow Leopard Working Secretariat, 2013) currently being implemented, more appropriate in the context of snow leopard and wild ungulate conservation in the Indian Himalaya.

\section{Acknowledgements}

We thank the Himachal Pradesh Forest Department (Wildlife Wing) for financial and logistical support; James 
E. Hines for valuable inputs at various stages of the work and during preparation of the manuscript; our survey respondents for their kind cooperation; and Lobzang Gialson for invaluable assistance during field work. The Whitley Fund for Nature has been a long-term supporter of our research and conservation work, and we are thankful for support from the Whitley-Fondation Segré Partnership Fund.

\section{Author contributions}

AG, KS and YVB designed the study. AG conducted the field work and wrote the article. AG, KS, KRS, YVB and $\mathrm{RR}$ analysed the data. YVB, BP, CM, KS and KRS reviewed the article.

\section{References}

AкаIKe, H. (1973) Information theory as an extension of the maximum likelihood principle. In Second International Symposium on Information Theory (eds B.N. Petrov \& F. Csaki), pp. 267-281. Akaemiai Kiado, Budapest, Hungary.

Axelby, R. (2007) 'It takes two hands to clap': how Gaddi shepherds in the Indian Himalayas negotiate access to grazing. Journal of Agrarian Change, 7, 35-75.

BagChi, S., Mishra, C. \& Bhatnagar, Y.V. (2004) Conflicts between traditional pastoralism and conservation of Himalayan ibex (Capra sibirica) in the Trans-Himalayan mountains. Animal Conservation, 7, 121-128.

Basannagari, B. \& Kala, C.P. (2013) Climate change and apple farming in Indian Himalayas: a study of local perceptions and responses. PLoS ONE, 8(10), e77976.

Bhatnagar, Y.V., Mathur, V.B., Sathyakumar, S., Ghoshal, A., Sharma, R.K., Bijoor, A. et al. (2016) South Asia: India. In Snow Leopards. Biodiversity of the World: Conservation from Genes to Landscapes (eds T. McCarthy, D. Mallon \& P.J. Nyhus), pp. 457-470. Academic Press, London, UK.

Bhatnagar, Y.V. \& SingH, N.J. (2011) Nomadism in the Indian Changthang: changes and implications on society and biodiversity. In Global Change, Biodiversity and Livelihoods in Cold Desert Region of Asia, pp. 135-146. Bishen Singh \& Mahendra Pal Singh Publication, Dehradun, India.

Burnham, K.P. \& Anderson, D.R. (2002) Model Selection and Multimodel Inference. 2nd edition. Springer, New York, USA.

Ceballos, G., Ehrlich, P.R., Soberón, J., Salazar, I. \& Fay, J.P. (2005) Global mammal conservation: what must we manage? Science, 309, 603-607.

Champion, F.W. \& Seth, S.K. (1968) A Revised Survey of the Forest Types of India. Government of India Press, Nasik, India.

Das, A., Krishnaswamy, J., Bawa, K.S., Kiran, M.C., Srinivas, V., Kumar, N.S. \& Karanth, K.U. (2006) Prioritization of conservation areas in the Western Ghats, India. Biological Conservation, 133, 16-31.

Gaston, A.J., Garson, P.J. \& Hunter, Jr, M.L. (1983) The status and conservation of forest wildlife in Himachal Pradesh, Western Himalayas. Biological Conservation, 27, 291-314.

Hines, J.E. (2006) PRESENCE 2. Software to estimate patch occupancy and related parameters. United States Geological Survey, Patuxent Wildlife Research Center, Laurel, USA.
Http://www.mbr-pwrc.usgs.gov/software/presence.html [accessed 14 August 2017].

Jackson, R., Mallon, D., McCarthy, T., Chundaway, R.A. \& Haвiв, B. (2008) Panthera uncia. In The IUCN Red List of Threatened Species 2008: e.T22732A9381126. Http://dx.doi.org/10. 2305/IUCN.UK.2008.RLTS.T22732A9381126.en [accessed 14 July 2017].

Jayapal, R. \& Ramesh, K. (2010) Management Plan for Rupi-Bhaba Wildlife Sanctuary, Himachal Pradesh [April 2010-March 2015]. Wildlife Institute of India, Dehradun, India.

Johansson, Ö., Rauset, G.R., Samelius, G., McCarthy, T., Andrén, H., Tumursukh, L. \& Mishra, C. (2016) Land sharing is essential for snow leopard conservation. Biological Conservation, 203, 1-7.

Karanth, K.K., Nichols, J.D., Hines, J.E., Karanth, K.U. \& Christensen, N.L. (2009) Patterns and determinants of mammal species occurrence in India. Journal of Applied Ecology, 46, 1189-1200.

Lovari, S., Ventimiglia, M. \& Minder, I. (2013) Food habits of two leopard species, competition, climate change and upper treeline: a way to the decrease of an endangered species? Ethology, Ecology \& Evolution, 25, 305-318.

Lyngdoh, S., Shrotriya, S., Goyal, S.P., Clements, H., Hayward, M.W. \& HАвів, B. (2014) Prey preferences of the snow leopard (Panthera uncia): regional diet specificity holds global significance for conservation. PLoS ONE, 9(2), e88349.

MacKenzie, D.I., Nichols, J.D., Hines, J.E., Knutson, M.G., \& FrankLin, A.B. (2003) Estimating site occupancy, colonization, and local extinction when a species is detected imperfectly. Ecology, 84, 2200-2207.

MacKenzie, D.I., Nichols, J.D., Royle, J.A., Pollock, K.H., BAiley, L.L. \& Hines, J.E. (2006) Occupancy Estimation and Modeling: Inferring Patterns and Dynamics of Species Occurrence. Academic Press, San Diego, USA.

Madhusudan, M.D. \& Mishra, C. (2003) Why big, fierce animals are threatened: conserving large mammals in densely populated landscapes. In Battles Over Nature: Science and the Politics of Conservation (eds V. Saberwal \& M. Rangarajan), pp. 31-55. Permanent Black, New Delhi, India.

Margoluis, R. \& Salafsky, N. (2001) Is Our Project Succeeding? A Guide to Threat Reduction Assessment for Conservation. Biodiversity Support Program, Washington, DC, USA.

McCarthy, T. \& Mallon, D. (eds) (2016) Snow Leopards. Biodiversity of the World: Conservation from Genes to Landscapes. Academic Press, London, UK.

Michalski, F. \& Peres, C.A. (2005) Anthropogenic determinants of primate and carnivore local extinctions in a fragmented forest landscape of southern Amazonia. Biological Conservation, 124, 383-396.

Mishra, C. (2000) Socioeconomic transition and wildlife conservation in the Indian Trans-Himalaya. Journal of the Bombay Natural History Society, 97, 25-32.

Mishra, C. (2001) High altitude survival: conflicts between pastoralism and wildlife in the Trans-Himalaya. $\mathrm{PhD}$ thesis. Wageningen University, The Netherlands.

Mishra, C., Bagchi, S., Namgail, T. \& Bhatnagar, Y.V. (2010) Multiple use of trans-Himalayan rangelands: reconciling human livelihoods with wildlife conservation. In Wild Rangelands: Conserving Wildlife While Maintaining Livestock in Semi-Arid Ecosystems, 1st edition (eds J.T. du Toit, R. Kock \& J.C. Deutsch), pp. 291-311. Blackwell Publishing, Oxford, UK.

Mishra, C., Madhusudan, M.D. \& Datta, A. (2006) Mammals of the high altitudes of western Arunachal Pradesh, eastern Himalaya: an assessment of threats and conservation needs. Oryx, 40, 29-35. 
Pillay, R., Johnsingh, A.J.T., Raghunath, R. \& Madhusudan, M. D. (2011) Patterns of spatiotemporal change in large mammal distribution and abundance in the southern Western Ghats, India. Biological Conservation, 144, 1567-1576.

Project Snow Leopard (2008) Project Snow Leopard. Ministry of Environment \& Forests, Government of India, New Delhi, India.

Rana, R.S., Bhagat, R.M., Kalia, V. \& LaL, H. (2012) The impact of climate change on a shift of the apple belt in Himachal Pradesh. In Handbook of Climate Change and India (ed. N.K. Dubash), pp. 51-62. Earthscan, Abingdon, UK.

SABerwal, V.K. (1996) Pastoral politics: Gaddi grazing, degradation, and biodiversity conservation in Himachal Pradesh, India. Conservation Biology, 10, 741-749.

Sanderson, E.W., Jaiteh, M., Levy, M.A., Redford, K.H., Wannebo, A.V. \& Woolmer, G. (2002) The human footprint and the last of the wild. BioScience, 52, 891-904.

Simberloff, D. (1998) Flagships, umbrellas, and keystones: is single-species management passé in the landscape era? Biological Conservation, 83, 247-257.

SingH, N.J. \& BAGCHI, S. (2013) Applied ecology in India: scope of science and policy to meet contemporary environmental and socio-ecological challenges. Journal of Applied Ecology, 50, 4-14.

Snow Leopard Network (2014) Snow Leopard Survival Strategy. Revised 2014 Version. Snow Leopard Network, Seattle, USA.

Snow Leopard Working Secretariat (2013) Global Snow Leopard and Ecosystem Protection Program. Bishkek, Kyrgyz Republic.

Suryawanshi, K.R., Bhatnagar, Y.V. \& Mishra, C. (2012) Standardizing the double-observer survey method for estimating mountain ungulate prey of the endangered snow leopard. Oecologia, 169, 581-59o.
Suryawanshi, K.R., Bhatnagar, Y.V., Redpath, S. \& Mishra, C. (2013) People, predators and perceptions: patterns of livestock depredation by snow leopards and wolves. Journal of Applied Ecology, 50, 550-560.

Symonds, M.R.E. \& Moussalli, A. (2011) A brief guide to model selection, multimodel inference and model averaging in behavioural ecology using Akaike's information criterion. Behavioral Ecology and Sociobiology, 65, 13-21.

Taubmann, J., Sharma, K., Uulu, K.Z., Hines, J.E. \& Mishra, C. (2016) Status assessment of the Endangered snow leopard Panthera uncia and other large mammals in the Kyrgyz Alay, using community knowledge corrected for imperfect detection. Oryx, 50, 220-230.

USL (Upper Spiti Landscape) (2011) Management Plan for Upper Spiti Landscape Including the Kibber Wildlife Sanctuary. Himachal Pradesh Forest Department, Shimla and Nature Conservation Foundation, Mysore, India.

\section{Biographical sketches}

Авнisheк Ghoshal is interested in applied ecological research and community-based conservation. YASH VEER BHATNAGAR is interested in conservation and management of snow leopard habitat. BIVASH PANDAV is interested in landscape ecology and human-wildlife interactions. Koustuвн Sharma is interested in species distribution modelling and population ecology. Charudutt Mishra is interested in theoretical and applied research and community-based conservation. R. RAGHUNATH is interested in geographical information systems and remote sensing. Kulbhushansingh R. SuRyawanshi is interested in population ecology, prey-predator relationships and community-based conservation. 